\title{
Cognição Social em Crianças: Descobrindo a Influência de Crenças Falsas e Emoções no Comportamento Humano
}

\author{
Social Cognition on Children: Discovering the Influence of \\ False Beliefs and Emotions on Human Behavior
}

\author{
Suely de Melo Santana $a^{a}$ Antonio Roazzi ${ }^{\text {b* }}$ \\ ${ }^{a}$ Universidade Católica de Pernambuco, ${ }^{b}$ Universidade Federal de Pernambuco
}

\begin{abstract}
Resumo
O estudo investigou a compreensão das crianças sobre a influência de crenças e emoções no comportamento. Participaram 100 crianças de 4-5 anos, diferentes níveis socioeconômicos, ambos sexos, distribuídas em 04 grupos conforme a idade. Apresentou-se uma transferência inesperada de objeto, seguida de duas questões em condições distintas. Observou-se a teoria da mente em $56 \%$ delas, a partir dos 4 anos. A análise loglinear mostrou que fatores como idade e nível socioeconômico são preditores significativos de melhor desempenho. Comparando-se os resultados nas questões de crença falsa e emoção, foi observada melhora crescente conforme a idade, tendo a questão de emoção apresentado padrão mais elevado. Discutiu-se: 1) a capacidade em predizer e justificar emoções desenvolve-se mais cedo que a habilidade para inferir ações baseadas em crença falsa; 2) o modo de apresentação da questão não favorece o desempenho; e 3) a interferência do nível socioeconômico ocorre entre os 54-65 meses de idade.
\end{abstract}

Palavras-chave: Cognição social; psicologia popular; teoria da mente; crença falsa; emoção.

\begin{abstract}
The study had investigated the children's comprehension of the influence of beliefs and emotions on human behavior. Participated 100 children, from 4 and 5 years old, different socioeconomic levels, both genders, distributed in 4 groups according to the age in months. The results was an unexpected object transference, followed by two questions in different conditions. Observed the theory of mind occurs in $56 \%$ of the them, starting at 4 years old. The loglinear analysis showed that the factors age and socioeconomic level are meaningful predictors of a better performance. Comparing the results in the questions of false belief and emotion, it was observed an increasing improvement in the development according to age, but in the question of emotion it showed a higher standard. It is discussed: (1) the capacity in predicting and justifying emotions is developed earlier than the ability to infer actions based upon false belief, (2) the way to pose the question did not help the performance and (3) the interference of SES occurs between 54-65 months of age.

Keywords: Social cognition; folk psychology; theory of mind; false belief; emotion.
\end{abstract}

Castelo-Branco, Frazão, Menéres, e Lourenço (2001) salientam que a década de 1980 demarca o início dos estudos sobre a teoria da mente propriamente dita. A referência experimental originou-se no campo da cognição animal a partir do questionamento sobre a possibilidade dos chimpanzés serem hábeis em atribuir estados mentais a si e aos outros, por meio da interpretação da intenção de um ator humano. O experimento gerou um paradigma formal que conduziu os psicólogos austríacos Wimmer e Perner (1983) à construção de uma tarefa de transferência inesperada para caracterizar a situação de crença falsa que veio a se tornar clássica nesta área (Ex: Astington \& Gopnik, 1991; Astington, Harris, \& Olson, 1988; Castelo-Branco et al., 2001). Sendo assim, a expressão crença falsa significa uma

Agradecimentos: Às escolas pela viabilidade e disponibilidade e às crianças. Artigo parte da dissertação de Mestrado (PPG Psicologia Cognitiva - UFPE). Apoio: CNPq ('Bolsa de mestrado).

${ }^{*}$ Endereço: UNICAP/CTCH, $7^{\circ}$ andar, Rua do Príncipe, 526, 50050 900, Recife, PE. ssantana@unicap.br crença que diverge da realidade por estar pautada em informações perceptuais parciais sobre uma dada situação.

Os teóricos que pressupõem uma aquisição mais precoce da teoria da mente (Ex.: Wellman, 1988), argumentam que a teoria da mente emerge por volta dos 2 - 3 anos de idade quando, em geral, a criança torna-se capaz de atribuir estados mentais a si e aos outros. Para os defensores de uma aquisição mais tardia (Ex.: Perner, 1991), a manifestação explícita desta capacidade surge apenas entre os 4 e 5 anos de idade, quando a criança se torna capaz de lidar com crenças falsas, conseguindo manipular todo um sistema de representações, das mais simples às mais complexas, ou seja, quando já consegue metarrepresentar (Castelo-Branco et al., 2001). De modo mais consistente, considera-se que uma explicitação genuína de uma teoria da mente construtivista torna-se evidente apenas na idade escolar, a partir dos 6-7 anos, sendo mais próxima da teoria da mente adulta apenas a partir do período da adolescência. Chandler (1988), por exemplo, 
defende que neste período as crianças começam não apenas a compreenderem que diferentes pessoas podem ter diferentes crenças, mas também que essas pessoas podem saber a mesma coisa de modos diferentes.

Em termos da habilidade em lidar com as crenças falsas, a dificuldade expressa pela criança de 3 anos de idade estaria associada, conforme Lourenço (1992), a três hipóteses explicativas básicas que se relacionam com fatores cognitivos e lingüísticos. Estas hipóteses são designadas por conflito crença/desejo (Wellman \& Bartsch, 1988) - cujo esquema de raciocínio repousaria sobre a tríade crença, desejo e situação externa; déficit conceitual (Perner, Leekman, \& Wimmer, 1987) - que relaciona o insucesso nas tarefas de crença falsa à inabilidade para estabelecer metarrepresentações e a não partilha do significado lingüístico (Siegal \& Beattie, 1991)que atribui a dificuldade da criança de 3 anos à natureza do ambiente conversacional entre criança e adulto.

Astington (2000a) postula também, quanto aos fatores lingüísticos, a existência de uma estreita relação entre o desenvolvimento de uma teoria da mente em crianças ocidentais e o desenvolvimento da linguagem e da metalinguagem. Segundo ela, as habilidades metarrepresentacionais que repousam sobre a linguagem (universal biológico) permitiriam à criança representar uma crença falsa em oposição à representação perceptual fornecida pelo contexto atual. Em sua conclusão, alega que "metalinguagem provê as crianças com nosso modo cultural de explicitar essa distinção” (p.12).

Com relação à habilidade para identificar emoções básicas, Bretherton, McNew, e Beeghly-Smith (1981) defendem que há um desenvolvimento precoce, já em torno dos 20 meses de idade enquanto Harris, Johnson, Hutton, Andrews, e Cooke (1989) afirmam que entre os 3 e 7 anos de idade as crianças já reconhecem que as reações emocionais dependem da forma com que a pessoa apreende uma determinada situação.

Apesar da variedade de estudos realizados em diversos países (Ex.: Astington \& Gopnik, 1991; Baron-Cohen, Leslie, \& Frith, 1985; Halford, 1993; Hogrefe, Wimmer, \& Perner, 1986; Lourenço, 1992; Perner et al., 1987; Siegal \& Beattie, 1991; entre outros), no Brasil, são poucos os estudos na área de teoria da mente. Particularmente, utilizando tarefas de crença falsa, os estudos pioneiros foram realizados no Recife (PE), por Dias (1993); Dias, Soares, e Sá (1994) e Roazzi e Santana (1999).

No estudo de Dias (1993), a partir da adequação de tarefas de crença falsa tradicionais na área - a tarefa de Sally (BaronCohen et al., 1985) e a tarefa dos Smarties (Perner et al., 1987), foram investigadas 90 crianças de 4, 5 e 6 anos de idade, sendo 30 de orfanato, 30 de nível socioeconômico baixo e 30 de nível socioeconômico médio, com o objetivo de verificar a possível influência da cultura na habilidade das crianças predizerem ações e emoções baseadas nas crenças e desejos de outras pessoas. Os resultados indicaram que as crianças de nível socioeconômico baixo e médio, de 4 anos de idade, já apresentavam a habilidade desenvolvida, enquanto que só aos 6 anos de idade estes resultados foram verificados em crianças de orfanato.
Ao desenvolver uma nova investigação, Dias et al. (1994) hipotetizaram que o baixo desempenho das crianças de orfanato (Dias, 1983) foi influenciado pelos fatores lingüísticos e pela interação experimentador/criança. Para averiguar a adequação dessa hipótese, testaram 30 crianças de orfanato, com idade variando entre 4, 5 e 6 anos, utilizando as mesmas tarefas do estudo anterior, modificadas em termos de estrutura lingüística do questionamento, assim como uma maior interação experimentador/criança. As autoras compararam os resultados obtidos nos dois estudos, observando um desempenho similar ao das crianças de nível socioeconômico médio e baixo, assim como desempenhos significativamente maiores que as crianças de orfanato do estudo anterior. Com isso, confirmaram que uma maior interação examinador-criança e uma linguagem adequada contribuíram para o bom desempenho das crianças no referido estudo.

Com o objetivo de verificar a influência da idade, do sexo e do tipo de ator envolvido (animado e inanimado) na capacidade de compreender tarefas de crença falsa, Roazzi e Santana (1999) realizaram um estudo com 72 crianças entre 4 e 5 anos de idade, de nível socioeconômico médio, baseado na tarefa tradicional de Sally. Eles utilizaram três tipos de questões que demandavam níveis diferenciados de interpretação, uma vez que pensar sobre o pensamento de alguém parece exigir um grau mais sofisticado de elaboração do pensamento do que opinar sobre a realidade concreta (Ex.: Perner, 1991). Consoante com essa avaliação, os dados obtidos levaram à conclusão de que as crianças de 4 anos obtiveram um desempenho significativamente melhor no questionamento sobre a realidade concreta do que sobre o pensamento de outro. Estes autores não encontraram diferenças significativas quanto ao sexo, nem quanto ao tipo de ator envolvido, se animado ou inanimado. Diferentemente dos resultados obtidos nos estudos de Dias (1993) e Dias et al. (1994), que indicaram uma emergência da teoria da mente já aos 4 anos de idade, tanto para crianças de classe média, baixa ou de orfanato, Roazzi e Santana (1999) constataram que só a partir dos 5 anos de idade as crianças de nível socioeconômico médio apresentaram uma teoria da mente já desenvolvida.

As controvérsias empíricas observadas nos três estudos quanto ao período de aquisição da teoria da mente, a interferência da variação lingüística e do fator socioeconômico no desempenho das crianças em tarefas de crença falsa, bem como a impossibilidade de se compararem os resultados, devido às diferenças de métodos utilizados, suscitaram a importância de realizar um novo estudo, adotando um único método para investigar estas questões.

Esta razão fez surgir três questionamentos: 1) Em que período, realmente, a criança evidencia uma explícita teoria da mente? - Já que alguns estudos na literatura (Dias, 1993; Dias et al., 1994; Wellman \& Bartsch, 1988, entre outros) apontam para a presença desta habilidade por volta dos 3 4 anos de idade, enquanto outras investigações (Chandler, 1989; Roazzi \& Santana, 1999) indicam que, de uma maneira mais complexa, a teoria da mente só emerge a partir dos 5 - 6 
anos de idade; 2) O fator socioeconômico exerce alguma influência na expressividade da teoria da mente? Considerando-se para esta questão o fato de que esta variável interfere no desempenho das crianças pré-escolares em tarefas variadas (Carraher, 1989; Carraher, Carraher, \& Schliemann, 1988; Dias, 1993); e, 3) Que tipo de relação observa-se entre a habilidade para atribuir emoções e a expressão da teoria da mente? - Já que na literatura (Harris et al., 1989; Wellman \& Bartsch, 1988, entre outros) observase um desenvolvimento mais precoce da habilidade em predizer emoções quando comparada à capacidade de realizar inferências com base em crenças falsas.

\section{Método}

\section{Participantes}

A amostra foi composta por 100 crianças de uma escola privada (nível socioeconômico médio) e de uma creche pública (nível socioeconômico baixo), sendo distribuída em quatro grupos, de acordo com a idade em meses. Foram alocadas 27 no primeiro grupo, com idade variando entre 48 e 53 meses, no segundo grupo um total de 24 participantes, entre 54 e 59 meses, no terceiro foram agrupadas 30 crianças, de 60 a 65 meses e no quarto grupo um total de 19 participantes, entre 66 e 71 meses.

Para o nível socioeconômico baixo, obteve-se tanto na condição modificada quanto na tradicional a mesma idade média de 50 meses para o grupo $1(d p=2,0, d p=2,37$, respectivamente para cada condição) e para o grupo 2 uma idade média de 56 meses $(d p=0,82, d p=2,08$, respectivamente). Para o grupo 3 uma idade média de 63 meses $(d p=0,8$ para a condição modificada) e uma idade média de 62 meses ( $d p=1,96$, para a condição tradicional) e para o grupo 4 uma idade média de 68 meses $(d p=1,72$, condição modificada) e uma idade média de 69 meses ( $d p=1,73$, condição tradicional). Para o nível socioeconômico médio, obteve-se tanto na condição modificada quanto na tradicional a mesma média de idade (em meses) para o grupo $1(m=51, d p=2,63, d p=1,48$, respectivamente), variando um pouco para o grupo $2(m=58$ meses, $d p=1,25, m=57$ meses, $d p=1,21$, respectivamente). Para o grupo 3 a mesma média para ambas condições $(m=62$ meses, $d p=2,18, d p=1,83$, respectivamente) e também para grupo 4 ( $m=67$ meses, $d p=1,0, d p=1,30$, respectivamente).

\section{Material}

O material utilizado no experimento consistiu em 02 bonecas estilo Barbie (0 1 loira e 01 morena, cerca de $27 \mathrm{~cm}$ de altura cada), 01 anel, 01 cestinha ( $6 \mathrm{~cm}$ de diâmetro) e 01 caixinha $(6 \times 5 \mathrm{~cm})$ confeccionadas em material emborrachado (EVA) e ambas com tampa.

\section{Procedimento}

A coleta de dados foi realizada durante os meses de abril e maio de 2000. O procedimento contemplou a utilização de uma situação-problema, adaptada a partir da tarefa de Sally, do estudo de Baron-Cohen et al. (1985), da qual foram elaboradas uma forma de questionamento tradicional (Condição 1) e uma forma de questionamento modificada (Condição 2). As expressões lingüísticas utilizadas, conforme sugestões da literatura (Siegal \& Beattie, 1991) foram C1 procurar, $\mathrm{C}_{2}$ - procurar em primeiro lugar.

A tarefa foi aplicada individualmente por um experimentador (E) e cada criança foi avaliada apenas em uma condição; sendo todas as entrevistas gravadas e posteriormente transcritas. Inicialmente, o experimentador convidou a criança para participar do experimento, informando que iria apresentar-lhe umas bonecas, contar uma história sobre elas e fazer algumas perguntas. Informou ainda que não havia resposta certa ou errada, e que a criança deveria responder o que considerasse correto. A alocação das crianças na condição 1 ou 2 foi realizada aleatoriamente, respeitando-se os critérios para uma distribuição amostral eqüitativa.

Foram adotadas três duplas de nomes na história, com o intuito de evitar a possível interferência da troca de informações entre as crianças, em sala de aula, sobre a situação-problema apresentada. Assim, foram utilizados de maneira randomizada os seguintes pares de nomes: Mariana/Alice, Xuxa/Mara, Fátima/Luciana.

Antes de apresentar a história, o experimentador fazia a demonstração para familiarizar a criança com o material. Após essa demonstração, o experimentador solicitava à criança que respondesse às questões de controle, que serviram para checar se a criança realmente havia acompanhado a demonstração e conseguia identificar corretamente os personagens, associando-os aos seus respectivos objetos.

Após a criança ter respondido corretamente a todas as questões de controle, o experimentador informava à criança que iria apresentar uma história sobre as bonecas Mariana e Alice. A situação-problema, seguida dos questionamentos, era então apresentada à criança, de maneira narrada e encenada, conforme descrita a seguir:

Mariana e Alice são amigas e vão juntas passear no parque. Mariana leva sua cestinha e esconde seu anel dentro. Alice leva sua caixinha. Chegando ao parque, Mariana deixa sua cestinha e vai brincar. Alice, então, para fazer uma brincadeira com Mariana, abre sua cestinha, pega o anel e o esconde em sua caixinha. Em seguida, também sai para brincar. Mariana volta e quer brincar com seu anel.

\section{Tarefa de Crença Falsa e Emoção - Condição I (Tradicional)}

1. Aonde Mariana vai procurar por seu anel? Por que?

2. Como Mariana vai se sentir depois de procurar o anel neste lugar? (Alegre, Triste, com Raiva ou Feliz)? Por que?

3. Onde o anel está realmente?

Tarefa de Crença Falsa e Emoção - Condição II (Modificada)

1. Aonde Mariana vai procurar, em primeiro lugar, por seu anel? Por que?

2. Como Mariana vai se sentir depois de procurar o anel 
neste lugar? (Alegre, Triste, com Raiva ou Feliz)? Por que? 3. Onde o anel está realmente?

Para a segunda questão, caso a criança não fornecesse uma resposta de imediato, era oferecida uma escolha forçada para que a mesma fizesse sua opção dentre as emoções Alegre, Triste, com Raiva e Feliz. A ordem de apresentação das mesmas foi randomizada para evitar o efeito de ordem.

\section{Resultados}

Para tornar mais clara a categorização de uma resposta compatível ou não-compatível com a crença falsa do personagem, assim como de uma resposta de emoção aceitável ou inaceitável têm-se, a seguir, na Tabela 1, quatro exemplificações:

Foi adicionada à análise uma variável dependente que representa a ocorrência simultânea das respostas para a questão de crença falsa e emoção. Deste modo, foram adotadas quatro categorias: categoria $O$ - Não-Compatível/Inaceitável; categoria 1 - Não-Compatível/Aceitável; categoria 2 Compatível/Inaceitável e categoria 3 - Compatível/ Aceitável.

\section{Análise das Respostas à Questão sobre Crença Falsa}

Verificou-se que o desempenho apresentado pelos participantes de nível socioeconômico médio $(m=0,69$; $d p=0,47)$ foi melhor que o das crianças de nível socioeconômico baixo $(m=0,43 ; d p=0,50)$. Mais especificamente, observou-se também que, em ambos níveis socioeconômicos, as médias de respostas compatíveis tenderam a aumentar em função do aumento da idade, obtendo-se as seguintes médias e desvio-padrão: grupo 1 nível socioeconômico médio $(m=0,44, d p=0,53)$; nível socioeconômico baixo $(m=0,33, d p=0,49)$; grupo 2 - nível socioeconômico médio $(m=0,67, d p=0,49)$; nível socioeconômico baixo $(m 0,33, d p=0,50)$; grupo 3 - nível socioeconômico médio $(m=0,75, d p=0,45)$; nível socioeconômico baixo $(m=0,43, d p=0,51)$; grupo 4 - nível socioeconômico médio $(m=0,89, d p=0,33)$; nível socioeconômico baixo $(m=0,70, d p=0,48)$. Ao se considerar o desempenho das crianças apenas em função do tipo de condição e nível socioeconômico, foi constatado que as crianças de nível socioeconômico médio apresentaram uma

Tabela 1

Exemplificação das Categorias de Respostas às Questões de Crença Falsa e Emoção

\begin{tabular}{|c|c|c|}
\hline \multirow{5}{*}{$\begin{array}{l}\text { Pergunta } \\
\text { (Crença falsa) } \\
\text { Aonde Mariana vai procurar (em } \\
\text { primeiro lugar) por seu anel? Por } \\
\text { que? } \\
\text { (Emoção) } \\
\text { Como Mariana vai se sentir depois } \\
\text { de procurar o anel neste lugar? Por } \\
\text { que? }\end{array}$} & \multicolumn{2}{|c|}{ Resposta de crença falsa e emoção } \\
\hline & Compatível e Aceitável & Não-Compatível e Aceitável \\
\hline & $\begin{array}{l}\mathrm{R}-\mathrm{Na} \text { cestinha dela; porque ela escondeu } \\
\text { lá. } \\
\mathrm{R} \text {-Triste (ou com raiva); porque ela não } \\
\text { vai encontrar. }\end{array}$ & $\begin{array}{l}\mathrm{R}-\mathrm{Na} \text { caixinha; porque Alice trocou. } \\
\mathrm{R}-\text { Feliz (ou alegre); porque ela vai } \\
\text { encontrar. }\end{array}$ \\
\hline & Compatível e Inaceitável & Não-Compatível e Inaceitável \\
\hline & $\begin{array}{l}\mathrm{R}-\mathrm{Na} \text { cestinha; porque estava lá } \\
\text { primeiro. } \\
\mathrm{R} \text {-Alegre (ou feliz); porque ela vai achar o } \\
\text { anel. }\end{array}$ & $\begin{array}{l}\mathrm{R} \text { - Na caixinha; porque a outra boneca } \\
\text { escondeu. } \\
\mathrm{R} \text { - Triste (ou com raiva); porque ela não } \\
\text { vai achar; ou ainda... } \\
\mathrm{R} \text { - Nadando (ou não sel); porque... } \\
\text { porque... não sei. }\end{array}$ \\
\hline
\end{tabular}

média menor na condição tradicional do que na condição modificada (respectivamente, $m=0,67$ e 0,$72 ; d p=0,48$ e $0,47)$. Distintamente, as médias das crianças de nível socioeconômico baixo apresentaram-se bem semelhantes em ambas condições (respectivamente, $m=0,44$ e 0,$42 ; d p=0,51$ e 0,50$)$.

No intuito de averiguar a significância das respostas compatíveis com a crença falsa fornecidas pelas crianças de 4 anos ( 48 a 59 meses) quando comparadas com as de 5 anos de idade (60 a 71 meses), foi realizada uma análise nãoparamétrica, através do teste de Kruskal-Wallis, observandose um efeito significativo $\left(x^{2}=4,97\right.$; g.l., $\left.1, p<0,026\right)$. Ainda, correspondente aos 4 e 5 anos de idade foram encontradas as seguintes médias ordenadas, 45,05 e 56,17, respectivamente.

Para verificar os possíveis efeitos interativos da resposta à questão de crença falsa com as variáveis idade, condição e nível socioeconômico, foi computada uma análise loglinear de tipo hierárquico. Foi encontrada uma interação significativa da resposta à questão de crença falsa com idade $\left(x^{2}=7,82\right.$, g.l. 3, $\left.p=0,049\right)$ e nível socioeconômico $\left(x^{2}=6,39\right.$, g.l. $1, p=0,011)$.

\section{Análise das Respostas à Questão sobre Emoção}

O desempenho apresentado pelos participantes de nível socioeconômico médio $(m=0,94 ; d p=0,24)$ foi melhor que o das crianças de nível socioeconômico baixo $(m=0,88$; $d p=0,33)$. Mais especificamente, verificou-se também que, em ambos níveis socioeconômicos, as médias de respostas aceitáveis demonstraram um efeito quase teto, obtendo-se as seguintes médias e desvio-padrão: grupo 1 - nível socioeconômico médio $(m=1,0, d p=0)$; nível socioeconômico baixo ( $m=0,78, d p=0,43)$; grupo 2 - nível socioeconômico médio ( $m=0,87, d p=0,35)$; nível socioeconômico baixo ( $m=0,78, d p=0,44)$; grupo 3 - nível socioeconômico médio ( $m=0,94, d p=0,25)$; nível socioeconômico baixo $(m=1,0$, $d p=0)$; grupo 4 - nível socioeconômico médio e baixo ( $m=1,0$, $d p=0$ ). Considerando-se o desempenho em função da condição e níveis socioeconômicos, constatou-se que as crianças de nível socioeconômico médio apresentaram um desempenho semelhante em ambas condições, tradicional e modificada (respectivamente, $m=0,92 ; d p=0,28$ e $m=0,96$; $d p=0,020)$. As médias das crianças de nível socioeconômico baixo apresentaram-se distintas sendo, respectivamente, $m=0,92 ; d p=0,28$ e $m=0,85 ; d p=0,37$. ... não sei. 
Para verificar possíveis efeitos interativos entre a resposta à questão de emoção e as variáveis idade, condição e nível socioeconômico, foi computada uma análise loglinear de tipo hierárquico. Foi encontrada uma interação significativa da resposta à questão de emoção somente com idade $\left(x^{2}=7,61\right.$, g.l. $3, p=0,045)$.

A análise loglinear ratificou os resultados obtidos com relação à questão de emoção, apontando para a influência da idade no desempenho das crianças. Observou-se que, apesar desse tipo de resposta ter apresentado um efeito quase teto, uma melhoria em função da idade ainda pôde ser verificada.

\section{Análise Simultânea das Respostas à Questão sobre Crença Falsa e Emoção}

Para verificar os possíveis efeitos interativos desta variável dependente com as variáveis idade, condição e nível socioeconômico, foi computada uma análise loglinear do mesmo tipo já realizado anteriormente para as questões em separado. Foram encontradas interações significativas com as variáveis nível socioeconômico $\left(\mathrm{x}^{2}=7,83\right.$, g.l. 3 , $p=0,048)$ e idade $\left(x^{2}=16,41\right.$, g.l. $\left.9, p=0,049\right)$.

Conforme se pode observar na Figura 1, esta interação entre as categorias e o nível socioeconômico foi mais predominante, para as crianças do nível socioeconômico baixo, nas categorias 1 e 3 , enquanto que, para as crianças do nível socioeconômico médio, a categoria 3 foi bem mais freqüente.

A influência exercida pela idade sobre a ocorrência simultânea das respostas às questões de crença falsa e emoção pode ser visualizada através da Figura 2. Observa-se que há uma tendência crescente da categoria 3 - compatível/ aceitável, demonstrando uma predominância quase absoluta no grupo 4 (66 a 71 meses), diferentemente do movimento decrescente evidenciado pelas demais categorias.

As análises levadas a efeito até o presente momento, vem a respaldar, por meio de comparações variadas, a influência da idade e do nível socioeconômico no melhor desempenho das crianças em relação às questões de crença falsa e emoção.

\section{Discussão}

Os resultados obtidos na presente investigação indicaram que a habilidade das crianças em predizer ações baseadas na crença falsa, já está presente por volta dos 4 anos de idade. Esta constatação veio a ratificar os achados de Dias (1993; Dias et al., 1994), bem como se encontra em consonância com outros estudos na área (Ex.: Wimmer \& Perner, 1983). O desempenho na questão de crença falsa, contudo, apontou para a influência significativa que os fatores como idade e nível socioeconômico comportam. A interferência dessas variáveis sustentou-se claramente através das análises realizadas, nas quais estes dois fatores apresentaram-se como preditores de um bom desempenho nesta questão. No geral, quando se avaliou o desempenho em função da idade e do nível socioeconômico, a compatibilidade com a crença falsa da personagem se

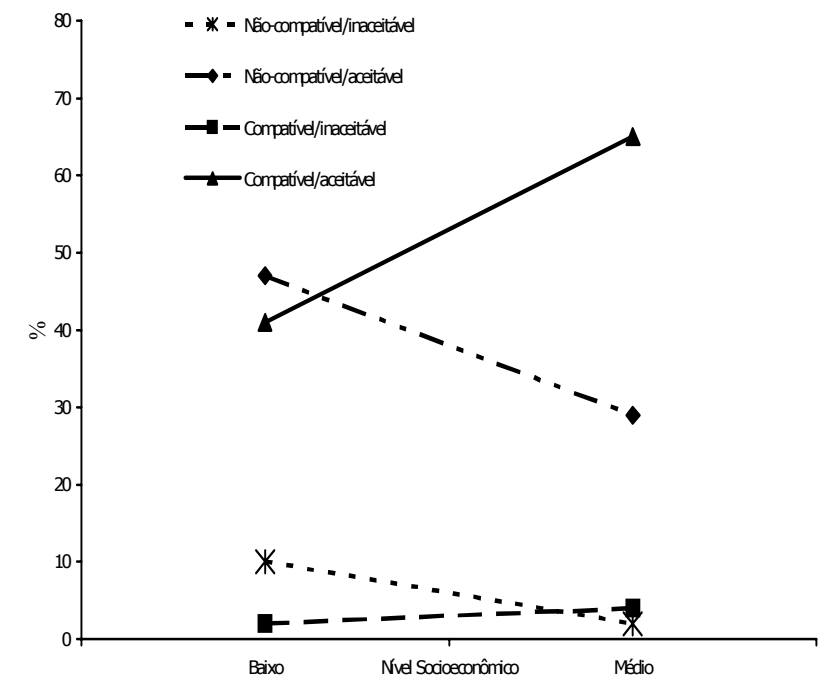

Figra 1. Categorias simutâneas de respostas emfuncão do nivel socioeconônico.

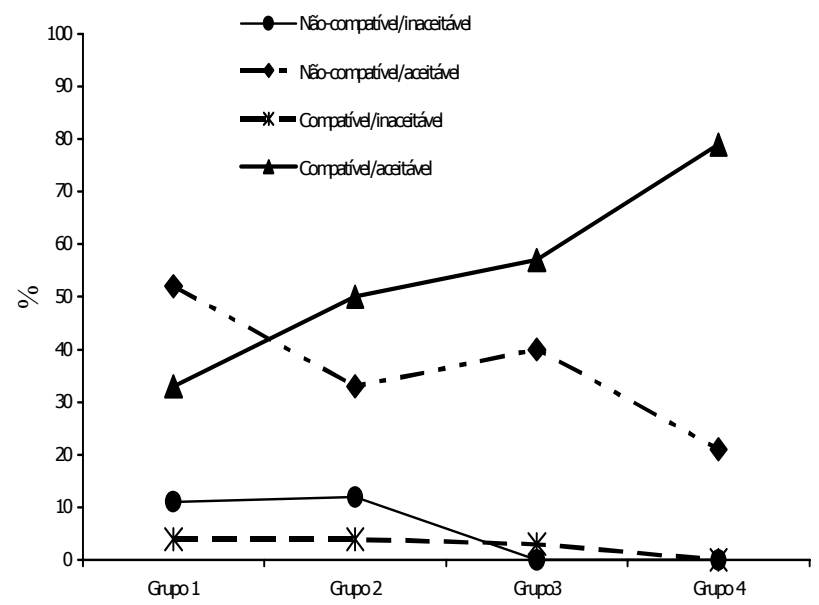

Figura 2 Categorias simultâneas de respostas em funcão da idade

apresentou bem mais nas escolhas das crianças de 5 anos e de nível socioeconômico médio do que nas escolhas realizadas pelas crianças de 4 anos de idade e de nível socioeconômico baixo.

Quando se observaram os desempenhos dos quatro grupos, evidenciou-se uma tendência crescente em direção às escolhas compatíveis com a crença falsa e que estas, em sua maioria, foram realizadas pelas crianças de nível socioeconômico médio. Porém, realizando uma análise mais sutil das médias observadas, pôde-se averiguar a existência de um padrão similar de respostas entre os níveis, que se tor nava bastante diferenciado nos grupos 2 e 3, e, ao chegar no grupo 4 (66 a 71 meses), tendia a uma maior aproximação entre os desempenhos apresentados pelas crianças dos dois níveis socioeconômicos. Desta forma, o comentário realizado por Roazzi, e Santana (1999) sobre a suscetibilidade do desempenho aos meses de idade, encontra respaldo nos dados da atual investigação, pela variabilidade crescente observada em função da idade. 
Partindo desta análise, pode-se sugerir, então, que o período crítico representado pelos grupos 2 e 3, ou seja, entre 54 e 65 meses, confere temporariamente um status mais vantajoso às crianças de nível socioeconômico médio, mas que as crianças de nível socioeconômico baixo conseguem em um curto período, alcançar uma melhoria que reduz esta aparente desvantagem. Sendo assim, esse status desfavorável do desempenho das crianças de nível socioeconômico baixo deve ser interpretado diferentemente de uma incapacidade ou uma inferioridade em termos intelectuais. Esta interferência do fator socioeconômico remete à polêmica e acirrada discussão, bem debatida por Carraher (1989), em torno das concepções antagônicas de déficit versus defasagem intelectual das crianças de classe menos favorecida. Em linhas gerais, ela pontua que as diferenças encontradas nos mais variados estudos que investigam os processos psicológicos comparando grupos sociais distintos, devem ser interpretadas à luz dos seguintes argumentos e evidências, que não são excludentes entre si: 1) acesso diferenciado aos "amplificadores culturais" (Bruner, 1973; citado em Carraher, 1989), ou seja, aos instrumentos que ampliam a capacidade de ação humana, tais como os sistemas simbólicos; 2) a cultura do silêncio (Freire, 1967; citado em Carraher, 1989) que, de maneira bastante sucinta, representa um conjunto de pensamentos e conduta que as pessoas da classe menos favorecida internalizam a partir da relação com a classe dominante; 3) suscetibilidade lingüística à situação escolar e de exame (Labov, 1972; Roazzi, 1988; citados em Carraher, 1989); 4) espontaneidade e expressividade lingüística diferenciadas (Carraher, 1985; citado em Carraher, 1989); 5) qualidade dos conteúdos abordados na pré-escola (Rego, 1989; citado em Carraher, 1989), 6) divergências nos processos de alfabetização, na medida em que, na convivência com adultos falantes de um certo dialeto, a criança está mais ou menos próxima da linguagem escrita que representa a norma padrão culta, apresentando uma diferença de acesso aos textos escritos (Soares, 1985; citado em Carraher, 1989); e, principalmente, 7) a consideração de que o processo de alfabetização das crianças recifenses de classe favorecida vem a ocorrer durante a pré-escola, enquanto que as menos favorecidas apenas iniciam seu processo formal de alfabetização na $1^{\mathrm{a}}$ série (Carraher \& Schliemann, 1983; citado em Carraher, 1989).

Um outro fator que parece influenciar nessa diferenciação e configura-se consoante com a consideração de Carraher e Schliemann (1983; citado em Carraher, 1989), remete ao argumento fornecido por Astington (2000a), de que o desenvolvimento da teoria da mente mantém estreita relação com o desenvolvimento da linguagem e, mais especificamente, da metalinguagem. Esta autora assinala que as crianças apresentam um uso espontâneo de verbos metalingüísticos (Ex.: pensar) em situações naturalísticas antes de apresentarem um bom desempenho nas tarefas de crença falsa, evidenciando que a apreensão completa do significado de termos lingüísticos ocorre apenas gradualmente (Nelson, 1996, citado em Astington, 200ob). Em sua concepção, as habilidades metarrepresentacionais permitem à criança representar uma crença falsa oposta à representação perceptual da situação atual, favorecendo-a com um modo cultural de explicitar essa diferença. Ora, esses argumentos vêm a legitimar a interpretação de que as diferenças encontradas possivelmente vinculam-se ao processo de alfabetização mais precoce das crianças de nível socioeconômico médio, que acaba por estimular o desenvolvimento da linguagem e da metalinguagem, favorecendo a apreensão dos significados de termos lingüísticos, fazendo com que a suscetibilidade ao contex to torne-se menos significativa, a ponto de aproximar o desempenho em situações escolar ou de exame ao desempenho em situações naturalísticas. Esta interpretação encontra significação nos resultados, na medida em que a desvantagem apresentada pelas crianças de nível socioeconômico baixo tende a desaparecer entre as crianças mais velhas.

A hipótese correspondente à não partilha do significado entre criança e experimentador, não se legitimou através da adequação da expressão lingüística, procurar em primeiro lugar, na condição modificada. Nesta investigação, os desempenhos não foram alterados significativamente, nem tampouco preditos, em função desta variável, tendo assim uma divergência tanto com os achados de Dias et al. (1994), quanto com os de Siegal e Beattie (1991) e de Lourenço (1992), já que os referidos autores salientam que a utilização dessa expressão facilitaria a compreensão da criança acerca do questionamento do examinador, favorecendo seu desempenho. Uma questão que se põe interessante aqui, e que também já foi suscitada por outros autores (Ex.: Campbell, 2000; Halford, 1993), relaciona-se com a diferença de requisito inferencial posto entre distintas situaçõesproblema.

A análise da questão emocional indicou que a capacidade de atribuir uma emoção básica à outra pessoa, levando em consideração o contexto, apresentou-se bem desenvolvida aos 4 anos de idade, independentemente do nível socioeconômico da criança. Desde o primeiro grupo (48 a 53 meses) já se observou um desempenho com tendência a tornar-se cada vez melhor, sendo indicado o fator idade em meses como preditor desse bom desempenho apresentado pelas crianças em geral. Estes achados convergem com outros dados encontrados na literatura, que apontam para uma capacidade precoce para identificar emoções básicas, já em torno dos 20 meses de idade (Bretherton, McNew, \& Beeghly-Smith, 1981) com tendência a desenvolver-se, evolutivamente, para uma predição de reações emocionais com base num raciocínio crença-desejo, por volta dos 4 anos (Wellman, \& Bartsch, 1988). No geral, esses dados também convergem com os resultados dos estudos de Harris et al. (1989), tanto no sentido de que entre os 3 e 7 anos de idade as crianças reconhecem que as reações emocionais dependem da forma com que a pessoa apreende uma determinada situação, como na constatação de que a idade exerce influência na predição da reação emocional. 
Tentando identificar o tipo de relação que se estabelece entre a habilidade em lidar com crenças falsas e a atribuição das emoções, constatou-se, por um lado, uma certa similaridade entre os processos, na medida em que ambas apresentaram uma tendência crescente em função dos meses de idade e, por outro, uma característica temporalmente assincrônica, uma vez que a habilidade para lidar com as emoções apresentou-se bem mais desenvolvida desde o início, denotando um processo de desenvolvimento que antecede ao da habilidade com as crenças falsas, abrindo espaço para a suposição de que parece haver uma relação de influência unilateral do desenvolvimento dos processos emocionais sobre o da habilidade em lidar com crença falsa. Em outras palavras, poder-se-ia alegar que ao lidar primeiramente com representações emocionais distintas, tornando-se hábil para atribuí-las adequadamente em função de um dado contexto, a criança também iria se instrumentalizando, mais consistentemente, para a representação de crenças conflitantes e, conseqüentemente, para a predição de um comportamento mais adequado em função desse mesmo contexto. Sendo assim, a atribuição adequada de emoções seria evolutivamente mais precoce e desenvolvimentalmente envolveria alguns processos cognitivos mais simples, do que a atribuição adequada de uma ação de acordo com a situação.

A relação interativa que esta investigação vem a sinalizar em torno da habilidade em atribuir emoções e a de lidar com crenças falsas, permite respaldar, de modo consoante, a concepção defendida por Vygotsky (1998) sobre a importância das dimensões afetiva e cognitiva para a formação da consciência, ligadas por uma relação dinâmica de construção e reconstrução durante todo o processo de desenvolvimento. Uma outra consideração neste sentido vem da perspectiva de Damásio (2000), que considera as emoções enquanto processos que têm o papel de regular e preservar a vida do organismo - o que já favoreceria sua apreensão mais precoce, sendo determinadas biologicamente e dependentes de mecanismos cerebrais inatos e automatizados. Além desses aspectos, ele ressalta a importância do desenvolvimento e da cultura no produto final dessas emoções, seja adequando o indutor à determinada emoção, seja modelando alguns aspectos de sua expressão ou, ainda, moldando a cognição e os comportamentos decorrentes de sua mobilização. Contudo, estas ponderações vêm sugerir apenas uma relação facilitadora e contributiva das emoções para a expressão da teoria da mente, antes que uma relação de causalidade. Acredita-se pois, em consonância com outros autores (Ex.: Wellman \& Bartsch, 1988), que a habilidade para lidar com as crenças falsas deve envolver desenvolvimentalmente processos cognitivos mais complexos e, evolutivamente, mais tardios. Esta constatação parece conduzir a uma vinculação com a conquista da consciência ampliada (Damásio, 2000) que possibilita ao indivíduo chegar ao ápice de suas capacidades mentais.

\section{Referências}

Astington, J.W. (2000a). Constructivist to the Core: An introduction to the volume. In J.W. Astington (Ed.), Minds in the making: essays in honor of David R. Olson (pp.1-13). Oxford: Blackwell.

Astington, J.W. (2000b). Language and metalanguage in children's understanding of mind. In J.W. Astington (Ed.), Minds in the making: essays in honor of David R. Olson (pp.267-284). Oxford: Blackwell.

Astington, J.W. \& Gopnick, A. (1991). Theoretical explanations of children's understanding of the mind. British Journal of Developmental Psychology, 9, 7-31.

Astington, J.W., Harris, P.L., \& Olson, D.R. (Eds.) (1988). Developing theories of mind. Cambridge: Cambridge University Press.

Baron-Cohen, S., Leslie, A.M., \& Frith, U. (1985). Does the autistic child have a "theory of mind"? Cognition, 21, 37-46.

Bretherton, I., McNew, S., \& Beeghly, M. (1981). Early person knowledge as expressed in gestual and verbal communication: When do infants acquire a theory of mind'? In M.E. Lamb \& L.R. Sherod (Eds.), Infant social cognition (pp.333-373). Hilldale, NJ: Erlbaum.

Campbell, R.N. (2000). Content and the representation of belief and desire. In J.W. Astington (Ed.), Minds in the making: essays in honor of David R. Olson (pp.165-176). Oxford: Blackwell.

Carraher, T.N. (1989). Sociedade e inteligência. São Paulo: Cortez.

Carraher, T.N., Carraher, D.W., \& Schliemann, A.D. (1988). Na vida dez, na escola zero. São Paulo: Cortez.

Castelo-Branco, J., Frazão, P., Menéres, S., \& Lourenço, O. (2001). Teorias da mente: passado, presente e futuro. Psicologia, Educação e Cultura, 2, 367-397.

Chandler, M. (1988). Doubt and developing theories of mind. In J.W. Astington, P.L. Harris, \& D.R. Olson (Ed.), Developing theories of mind (pp.387-413). Cambridge: Cambridge University Press.

Damásio, A. (2000). O mistério da consciência: do corpo e das emoções ao conhecimento de si. São Paulo: Companhia das Letras.

Dias, M.G.B.B. (1993). O desenvolvimento do conhecimento da criança sobre a mente. Psicologia: Teoria e Pesquisa, 9, 587-600.

Dias, M.G.B.B., Soares, G.B., \& Sá, T.P. (1994). Conhecimento sobre a mente e compreensão sobre as intenções do experimentador. Psicologia Teoria e Pesquisa, 10, 221-229.

Halford, G.S. (1993). Children's Understanding: the development of mental models. Hillsdale, NJ: Lawrence Erlbaum.

Harris, P.L., Johnson, C.N., Hutton, D., Andrews, G., \& Cooke, T. (1989). Young children's theory of mind and emotion. Cognition and Emotion, 3, 379-400.

Hogrefe, G.J., Wimmer, H., \& Perner, J. (1986). Ignorance versus false belief: A developmental lag in attribution of epistemic states. Child Development, 57, 567-582.

Lourenço, O. (1992). Teoria da Mente na criança e o desenvolvimento de crenças falsas: falsas, de quem? Análise Psicológica, 4, 431-442.

Perner, J. (1991). Understanding the representational mind. Cambridge, MA.: Bradford Books/MIT.

Perner, J., Leekman, S.R., \& Wimmer, H. (1987). Three-year-olds difficulty with false belief: The case for a conceptual deficit. British Journal of Developmental Psychology, 5, 125-137.

Roazzi, A. \& Santana, S.M. (1999). Teoria da Mente: efeito da idade, do sexo e do uso de atores animados e inanimados na inferência de estados mentais. Psicologia: Reflexão छ Crítica, 12, 307-330. 
Siegal, M. \& Beattie, K. (1991). Where to look first for children's knowledge of false beliefs. Cognition, 38, 1-12.

Vygotsky, L.S. (1998). O desenvolvimento psicológico na infância (pp.79-106). São Paulo: Martins Fontes.

Wellman, H.M. (1988). First step in the child's theorizing about the mind. In J.W. Astington, P.L. Harris \& D.R. Olson (Eds.), Developing theories of mind (pp.64-92). Cambridge: Cambridge University Press.

Wellman, H.M. \& Bartsch, K. (1988). Young children's reasoning about beliefs. Cognition, 31, 239-277.

Wimmer, H. \& Perner, J. (1983). Beliefs about beliefs: Representation and constraining function of wrong beliefs in young children's understanding of deception. Cognition, 13, 103-128. 